\title{
Gender Differences in TRH-Stimulated TSH and Prolactin in Primary Degenerative Dementia and Elderly Controls
}

\author{
Maurice W. Dysken, Antoinette Falk, Becky Pew, \\ Michael Kuskowski, and Dean D. Krahn
}

We performed thyrotropin-releasing hormone (TRH) stimulation testing in 18 nondepressed patients with primary degenerative dementia $(10 \mathrm{M}, 8 \mathrm{~F}$; average age $\pm S D=$ $68 \pm 7)$ and 12 elderly controls $(7 M, 5 F$; average age $\pm S D=61 \pm 6)$. Six patients were retested approximately 2 years later. Initial Mini-Mental State Examination scores for patients ranged from 2 to 28 (average $\pm S D=18 \pm 6$ ) and the scores for the control subjects were all equal to 30 . Protirelin $(500 \mu \mathrm{g})$ was injected iv and blood was sampled at 0, 15, 30, 45, 60, and 90 min for thyrotropin-stimulating hormone (TSH) and prolactin (PRL). There were no significant differences between patients and controls in baseline T4, T3 uptake, TSH, or PRL. No significant differences were found between patients and controls for either TRH-stimulated TSH or PRL at all time points. Duration of illness, severity of dementia, and severity of depressive symptoms did not correlate significantly with stimulation test results. There were, however, significantly greater responses in stimulated TSH and PRL for women compared with men in both patients and controls. Upon repeat testing $(n=6), T R H$-stimulated TSH and PRL were not significantly different from the initial results.

\section{Introduction}

The thyrotropin-releasing hormone (TRH) stinulation test has been used to test hypothalamic-pituitary axis functioning in a variety of psychiatric disorders. A blunted thyrotropin-stimulating hormone (TSH) response $\left(\Delta \mathrm{TSH}_{\max }<5.0 \mu \mathrm{U} / \mathrm{ml}\right)$ has been observed most consistently in approximately $25 \%$ of patients with major depression, $50 \%$ of alcoholic patients in acuite withdrawal, and $30 \%$ of alcoholic patients abstinent for more than 2 years (Loosen 1985). Less consistent are TRH stimulation test results in patients with primary degenerative dementia (PDD) when compared with age-matched controls. The rationale for testing hypothalamic-pituitary axis functioning in PDD patients has been based on the finding of senile plaques and neurofibrillary tangles in the hypothalamus (Ishii 1966; McDuff and Sumi 1983). In addition, somatostatin deficiency, which has

From the Geriatric Research, Education, and Clinical Center, Minneapolis VA Medical Center, Minneopolis, MN; and the Department of Psychiatry, University of Michigan, Ann Arbor, MI.

Address reprint requests to Maurice W. Dysken, M.D., GRECC Program (11G), Minneapolis VA Medical Center, One Veterans Drive, Minneapolis, MN 55417.

Raceived September 30, 1989; revised December 27, 1989. 
been found in brain (Davies et al. 1980) and cerebrospinal fluid (CSF) (Raskin et al. 1986) in PDD patients, could produce an enhanced TSH response to TRH stimulation because sornatostatin normally inhibits TSH release (Vale et al. 1974). Previous studies have shown no difference in $\triangle T$ TSH between PDD patients and controls (El Sobky et al. 1986; Franceschi et al. 1988; Lampe et al. 1988; Peabody et al. 1986) or a blunted $\Delta T S H$ in patients (Sunderland et al. 1985; Thomas et a!. 1037). TRH-stimulated prolactin (PRL) has also been measured and has shown no difference between PDD patients and controls (Thomas et al. 1987), an augmented $\triangle P R L$ in patients (El Sobky et al. 1986; Peabody et al. 1986), or a blunted $\triangle P R L$ in patients (Newhouse et al. 1986). Because of these inconsistent results, we carried out TRH stimulation testing in nondepressed PDD patients and elderly controls.

\section{Methods}

We performed TRH stimulation testing in 18 outpatients who met both DSM-III criteria for PDD and NINCDS/ADRDA criteria for probable dementia. All patients participated in a comprehensive diagnostic assessment that included a physical and neurological examination, neuropsychological testing, screening laboratory evaluations, an electrocardiogram (ECG), and a computed tomography (CT) scan of the head. Exclusion criteria consisted of (1) a history of psychiatric or neurological disorders including substance abuse and major depression, (2) daily psychoactive drug use within the preceeding 4 months, (3) significant physical illnesses including thyroid disorders within the preceeding 4 weeks, and (4) a score of 16 or greater on the 21-item Hamilton Depression Scale (HAM-D). In addition, we carried out TRH stimulation testing in 12 healthy elderly control subjects who had no evidence of a dementing disorder and were free of any significant medical illnesses or psychiatric disorders. The control group was recruited from a group of spouses and friends of the patients with primary degenerative dementia. Potential controls were interviewed to obtain information about significant past and current medical and psychiatric illnesses. Potential controls were excluded if there was any evidence for thyroid dysfunction, e.g., individuals on replacement thyroid medication, recent alcohol abuse, or depression. In both patients and controls all central nervous system (CNS) active medications were tapered and discontinued for at least 4 weeks before performing the TRH stimulation test. Six of the PDD patients were available for repeat TRH stimulation testing, which occurred between 21 and 30 months after the initial study (average interval $\pm \mathrm{SD}=25 \pm 3$ ).

All subjects fasted from midnight until the end of the procedure. After arriving at the hospital in the morning, an indwelling i.v. canula was placed into an arm vein at approximately 8:30 AM and a 9-ml blood sample was taken for baseline T4, T3 uptake, TSH, and PRL immediately after insertion of the i.v. needle (Ferriani and de Sa 1985). Protirelin (500 $\mu \mathrm{g}$ ) was injected i.v. at 9:00 AM and 4-ml blood samples were taken for measurement of TSH and PRL at 15, 30, 45, 60, and 90 min following the injection. All subjects were recumbant during the procedure. Samples were centrifuged for $10 \mathrm{~min}$ at $2500 \mathrm{rpm}$; the serum samples were then separated and stored at $-20^{\circ} \mathrm{C}$ for subsequent analyses. Subjects left the hospital after completion of the study.

Both TSH and PRL were assayed by separate double antibody radioimmunoassay (RIA) procedures. The interassiny and intraassay coefficients of variation for $5 \mu \mathrm{IU} / \mathrm{ml}$ TSH (Kallestad Laboratories, Inc., Austin, TX) were $10.6 \%$ and $5.3 \%$, respectively. The interassay and intraassay coefficients of variation for 7-9 ng/ml PRL (Diagnostic 
Products Corp., Los Angeles, CA) were $8.6 \%$ and $4.4 \%$, respectively. The clinical laboratory measured baseline T4 and T3 uptake.

To determine differences in overail group response and in the rate of decline of stimulated TSH and PRL (statistical group interaction), repeated measures analyses of variance were done on $\triangle T S H$ and $\triangle P R L$ levels for the peak response and all succeeding time points. Two-sample $t$-tests were used to compare patient and control values for $\triangle T S H$ and $\triangle P R L$ at each individual time point. Analyses of covariance (gender X group) with age as the covariate were carried out to examine gender effects while removing the possible influence of age. The areas under the curve (AUC) for TSH and PRL were calculated by adding trapezoidal areas from time zero to the 90 -min time point. For those patients who had a repeat TRH stimulation test, matched sample $t$-tests were used to compare $\triangle T S H$ and $\triangle P R L$ at each individual time point.

\section{Results}

The PDD patients $(10 \mathrm{M}, 8 \mathrm{~F})$ ranged in age from 55 to 78 (average age \pm SD $=68 \pm$ 7 ) and the control subjects $(7 \mathrm{M}, 5 \mathrm{~F})$, from 52 to 72 (average age $\pm S D=62 \pm 7)(t$ $=5.9, p<0.05$ ). Mini-Mental State Examination (MiMSE) scores ranged from 2 to 28 (average MMSE score $\pm S D=18 \pm 6$ ) for patients and were all equal to 30 for the controls. The 21-item HAM-D scores in patients ranged from 2 to 10 (average HAM-D scores $\pm S D=6 \pm 2$ ) and the average duration of illness $\pm S D$ was $1.9 \pm 2.4$ years. The 6 patients $(4 \mathrm{M}, 2 \mathrm{~F})$ who were available for repeated TRH stimulation testing were restudied between 21 and 30 months (average interval $=25 \pm 3$ ) after the initial evaluation.

There were no significant differences between PDD patients and controls in baseline T4, T3 uptake, TSH, or PRL, all of which were within normal limits. No significant differences were observed between patients and controls for TRH-stimulated $\Delta T S H$ (Figure 1) and $\triangle P R L$ (Figure 2) at all time points. Only one patient and one control, both men, had a blunted $\triangle T S H$. The AUCs for TSH and PRL did not differ between patients and controls. Duration of illness, severity of dementia (MMSE), and severity of depressive symptoms (HAM-D) did not correlate significantly with the stimulation test results.

There was, however, a significant relationship between gender and stimulated TSH and PRL levels (Table 1). The $\Delta \mathrm{TSH}_{\max }$ peak $\left(30 \mathrm{~min}\right.$ ) and the $\triangle P R L_{\max }$ peak $(15 \mathrm{~min})$ were significantly greater for women than for men. Similarly, the AUCs for TSH and PRL were significantly greater for women than for men. Five patients, 4 of whom were women, had $\Delta \mathrm{TSH}_{\max }$ levels that were $1 \mathrm{SD}$ above the patient mean; 2 control subjects, a man and a woman, had $\Delta \mathrm{TSH}_{\max }$ levels that were $1 \mathrm{SD}$ above the control mean. In addition, analysis of covariance showed significantly enhanced TSH responsiveness in women compared with men at $15 \min [F(1,25)=7.9, p<0.01], 45 \min [F(1,25)=$ $8.7, p<0.01], 60 \min [F(1,25)=7.2, p<0.05]$, and $90 \min [F(1,25)=8.1, p<$ $0.01]$. PRL response was also significantly increased in women at $30 \mathrm{~min}[F(1,22)=$ $6.3, p<0.05], 45 \min [F(1,22)=6.3, p<0.05]$, and $60 \min [F(1,22)=4.6, p<$ $0.05]$, but not at $90 \mathrm{~min}[F(1,22)=1.1, p=$ NS]. The difference between TRHstimulated $\triangle T S H$ in female patients versus female controls (Table 1) did not reach statistical significance for $\Delta \mathrm{TSH}_{\max }$ peak $(30 \mathrm{~min})(t=1.9, p=0.09)$ or for AUC for TSH $(t=-2.1, p=0.06)$.

Of the 6 patients who were restudied, $4(2 \mathrm{M}, 2 \mathrm{~F})$ had deteriorated significantly with an average decline $( \pm S D)$ in the MMSE of $11 \pm 2[N=6, t(5)=-2.6, p<0.05]$. 


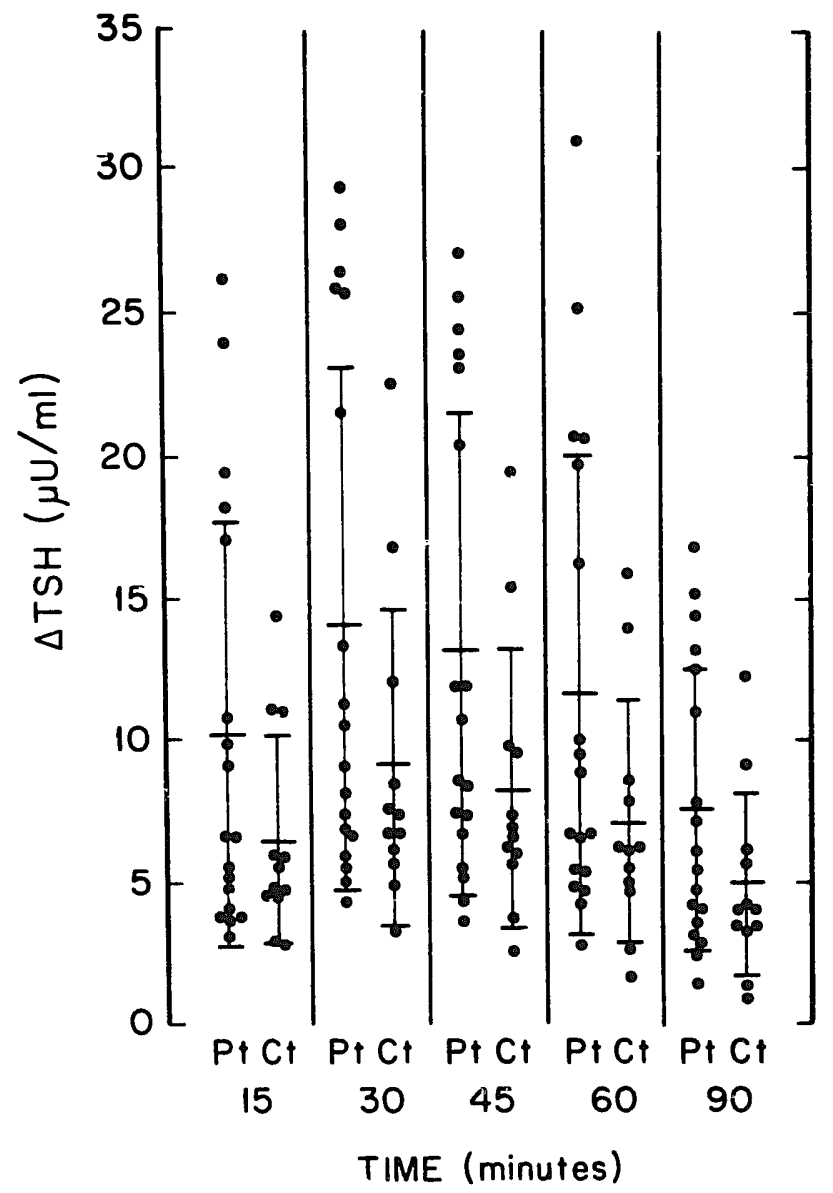

Figure 1. TRH-stimulated $\Delta$ TSH for patients (Pt) and controls (Ct) at $15,30,45,60$, and $90 \mathrm{~min}$.

The other 2 patients (2M) had remained stable: one patient had a decline of one MMSE point over 24 months, the other had an increase of 3 MMSE points over 30 months. No significant differences were observed between the initial and repeated TRH stimulation tests for either TRH-stimulated $\triangle T S H$ or $\triangle P R L$ at all time points. Also, the AUCs for TSH and PRL did not differ significantly between these two testing periods.

\section{Discussion}

Our findings are in agreement with those studies that did not find significant differences between PDD patients and age-matched controls in TRH-stimulated $\triangle T S H$ (El Sobky et al. 1986; Franceschi et al. 1988; Lampe et al. 1988; Peabody et al. 1986) and $\triangle P R L$ (Thomas et al. 1987). We did find, however, significantly greater responses in $\triangle T S H$ and $\triangle P R L$ for women compared with men in both the patient and control groups. Gender differences have been reported among normal euthyroid subjects for TRH-stimulated $\triangle T$ TSH and $\triangle$ PRL. Women tend to have a greater $\triangle T$ TSH (Ormston et al. 1971), which has not been found to change with age (Snyder and Utiger 1972a). In men, however, an age-associated decline in $\triangle$ TSH has been reported (Snyder and Utiger 1972b). These two patterns of TSH responsiveness to TRH in men and women would tend to accentuate gender differences as subjects age. In a recent study on TSH testing in a healthy elderly 


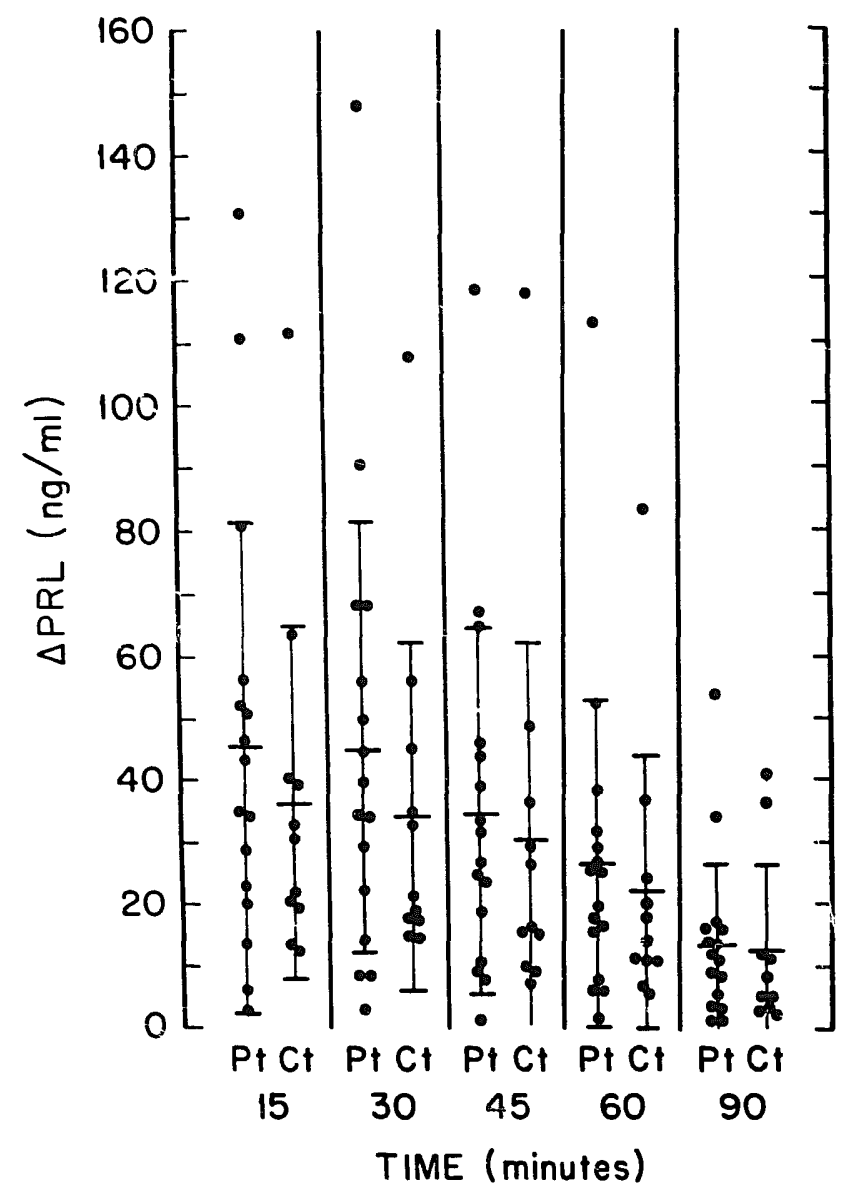

Figure 2. TRH-stimulated $\triangle P R L$ for patients $(\mathrm{Pt})$ and controls $(\mathrm{Ct})$ at $15,30,45,60$, and $90 \mathrm{~min}$.

Table 1. Gender Differences in TRH-stimulated $\triangle T S \mathrm{TS}_{\max }$ and $\triangle P R L_{\max }$ in Patients with Primary Degenerative Dementia and Age-matched Controls

\begin{tabular}{|c|c|c|c|}
\hline & $\begin{array}{c}\text { Men } \\
(M \pm S D)\end{array}$ & $\begin{array}{l}\text { Women } \\
(\mathrm{M} \pm \mathrm{SD})\end{array}$ & $\begin{array}{c}\text { ANCOVA } \\
F, p\end{array}$ \\
\hline $\begin{array}{l}\Delta \text { TSH }(30 \mathrm{~min}) \\
\text { Patients }(\mathrm{n}=18) \\
\text { Controls }(\mathrm{n}=12)\end{array}$ & $\begin{array}{l}9 \pm 6 \\
7 \pm 4\end{array}$ & $\begin{array}{l}20 \pm 9 \\
11 \pm 7\end{array}$ & $\begin{array}{c}F(1.25)=8.1 \\
p<0.01\end{array}$ \\
\hline $\begin{array}{l}\Delta \text { PFL }(15 \min ) \\
\text { Patients }(n=16) \\
\text { Controls }(n=11)\end{array}$ & $\begin{array}{l}30 \pm 18 \\
23 \pm 11\end{array}$ & $\begin{array}{l}66 \pm 44 \\
53 \pm 37\end{array}$ & $\begin{array}{c}F(1.22)=7.3 \\
p<0.05\end{array}$ \\
\hline $\begin{array}{r}\text { AUC (TSH vs time) } \\
\text { Patients }(\mathrm{n}=18) \\
\text { Controls }(\mathrm{n}=12)\end{array}$ & $\begin{array}{l}609 \pm 420 \\
497 \pm 298\end{array}$ & $\begin{array}{r}1374 \pm 588 \\
750 \pm 391\end{array}$ & $\begin{array}{c}F(1.25)=8.7 \\
p<0.01\end{array}$ \\
\hline $\begin{array}{r}\text { AUC (PRL vs time) } \\
\text { Patients }(\mathrm{n}=16) \\
\text { Controls }(\mathrm{n}=10)\end{array}$ & $\begin{array}{l}1969 \pm 1342 \\
1309 \pm 657\end{array}$ & $\begin{array}{l}3792 \pm 2874 \\
3344 \pm 2872\end{array}$ & $\begin{array}{c}F(1.21)=4.3 \\
p=0.05\end{array}$ \\
\hline
\end{tabular}


populatior, men showed a significantly diminished TSH response to TRH administration compared with women (Targum et al. 1989).

The PRL response to TRH has been reported to be greater in women than men, especially in young and middle-aged subjects (Iacobs et al. 1973). Among subjects of the same gender, $\triangle P R L$ responses were comparable from ages 20-80, although the response in elderly women was somewhat lower than that of the younger groups of women (Jacobs et al. 1973).

It is of interest that 2 PDD patients (MMSE $=28,21$ ) did not demonstrate cognitive decline when repeated testing was carried out after approximately 2 and $2 \frac{1}{2}$ years, respectively. Rates of progression for PDD do vary considerably and it is not uncommon for periods of relative cognitive stability to occur during the early course of the illness (Grady et al. 1988). Nevertheless, it is also known that at best, approximately $10 \%$ of patients with a clinical diagnosis of PDD will not meet autopsy or biopsy criteria for a pathological diagnosis of Alzheimer's disease (Riege and Metter 1988). Removing these two cognitively stable patients from the data set did not, however, change the overall results. The statistically significant gender differences were maintained for both $\Delta T S H$ and $\triangle P R L$, although $\triangle P R L$ at 60 min just missed retaining an alpha level of $0.05[F(1,20)$ $=3.97, p=0.06]$ as did the AÜC for PRL $[F(1,19)=3.8, p=0.06]$. Again, no significant differences were observed between patients and controls for TRH-stimulated $\triangle T S H$ and $\triangle P R L$ at all time points.

Our data suggest that the presence of primary degenerative dementia does not alter gender-associated differences in TSH and PRL responsiveness to TRH stimulation. Some of the previous TRH stimulation studies in Alzheimer's disease failed to show gender differences because either all the subjects were men (Lampe et al. 1988; Peabody et al. 1986) or gender differences were not examined for specifically (Newhouse et al. 1986; Thomas et al. 1987). One study did find a trend toward greater TSH responsiveness to TRH in women patients (Sunderland et al. 1985), but another study found no gender differences at all (El Sobky et al. 1986). In this latter study the timing of the blood collections were $20 \mathrm{~min}$ and $60 \mathrm{~min}$ after TRH administration. It is unlikely that the timing of blood samples for TSH measurement would account for these negative results as gender differences for TRH-stimulated TSH were found at all time points in our study.

\section{References}

El Sobky A, El Shazly M, Darwish AK, Davies T, Griftìn K, Keshaven MS (1986): Anterior pituitary response to thyrotrophin releasing hormone in senile dementia (Alzheimer type) and elder normals. Acta Psychiatr Scand 74:13-17.

Davies P, Katzman R, Terry RD (1980): Reduced somatostatin-like immunoreactivity in cerebral cortex from cases of Alzheimer's disease and Alzheimet senile dementia. Nature 288:279-280.

Ferriani RA, de Sa MFS (1985): Effect of venipuncture stress on plasma prolactin levels. Int $J$ Gynaecol Obstet 23:459-462.

Franceschi M, Perego L, Ferini-Strambi L, Smime S, Canal N (1988): Neuroendocrinological function in Alzheimer's disease. Nuuroendocrinology 48:367-370.

Grady CL, Haxby JV, Horwitz B, et al (1988): Longitudinal study of the early neurcpsychoiogical and cerebral metabolic changes in dementia of the Alzheimer type. J Clin Exp Neuropsychol 10:576-596.

Ishii T (1966): Distribution of Alzheimer's neurofibrillary changes it: the brain stem and hypothalamus of senile dementia. Acta Neuropathol 6:181-187.

Jacobs LS, Snyder PJ, Utiger RD, Daughday WH (1973): Prolactin response to thyrotropin-releasing hormone in normal suhjects. J Clin Endocrinol Metab 36:1069-1073. 
Lampe TH, Plymate SR, Risse SC, Kopeikin H, Cubberley L, Raskind M (1988): TSH responses to two TRH doses in men with Alzheimer's disease. Psychoneuroendocrinology 13:245-254.

Loosen PT (1985): The TRH-induced TSH response in psychiatric patients: A possible neuroendocrine marker. Psychoneuroendocrinology 10:237-260.

McDuff T, Sumi SM (1983): Subcortical degeneration in Alzheimer's disease. Neurology 33 (Suppl 2):159.

Newhouse PA, Sunderland T, Tariot PN, Mueller EA, Murphy DL, Cohen RM (1986): Prolactin response to TRH in Alzheimer's disease and elderly controls. Biol Psychiatry 21:963-967.

Ormston BJ, Garry R, Cryer RJ, Besser GM, Hall R (1971): Thyrotropin-releasing hormone as a thyroid-function test. Lancet ii:10-14.

Peabody CA, Minkoff JR, Davies HD, Winograd CH, Yesavage J, Tinklenberg JR (1986): Thyrotropin-releasing hormone stimulatior test and Alzheimer's disease. Biol Psychiatry 21:553556.

Raskin MA, Peskind ER, Lampe TH, Risse SC, Taborsky GJ, Dorsa DC (1986): Cerebrospinal fluid vasopressin, oxytocin, somatostatin, and $\beta$-endorphin in Alzheimer's disease. Arch Gen Psychiatry 43:382-388.

Riege WH, Metter EJ (1988): Cognitive and brain imaging measures of Alzheimer's disease. Neurobiol Aging 9:69-86.

Snyder PJ, Utiger RD (1972a): Thyrotropin response to thyrotropin releasing hormone in normal females over forty. J Clin Endocrinol Metab 34:1096-1098.

Snyder PJ, Utiger RD (1972b): Response io thyrotropin releasing hormone (TRH) in normal man. $J$ Clin Endocrinol Metab 34:380-385.

Sunderland T, Tariot PN, Mueller EA, Newhouse PA, Murphy DL, Cohen RM (1985): TRH stimulation test in dementia of the Alzheimer type and elder controls. Psychiatry Res 16:269275.

Targum SD, Marshall LE, Magac-Harris K, Martin D (1989): TRH tests in a healthy elderly population: Demonstration of gender differences. J Am Geriatr Soc 37:533-536.

Thomas DR, Hailwood R, Harris B (1987): Thyroid status in senile dementia of the Alzheimer type (SDAT). Acta Psychiatr Scand 76:158-163.

Vale W, Rivier C, Brazeau P, Guillemin R (1974): Effects of somatostatin on the secretion of thyrotropin and prolactin. Endocrinology 95:968-977. 